\title{
Familial developmental dysphasia
}

INSERM

\section{Source}

INSERM. (1999). Orphanet: an online rare disease and orphan drug data base. Familial developmental dysphasia. ORPHA:1799

Familial developmental dysphasia is a severe form of developmental verbal apraxia characterized by a deficit in spontaneous speech, writing, grammatical judgment and repetition, defective articulation, moderate to severe degree of dyspraxia, a reduced use of consonant clusters, and comprehension delay. Hearing and intelligence are normal. 